\title{
Optimal level of epidural block for perioperative analgesia in Nuss procedure
}

\author{
U. Fesenko', I. Myhal ${ }^{2}$, A. Albokrinov² \\ ${ }^{1}$ Danylo Halytsky Lviv National Medical University, Lviv, Ukraine \\ 2 Lviv Regional Children's Clinic Hospital, Lviv, Ukraine
}

\section{Background}

Pectus excavatum (PE) is the most frequent congenital deformity of thorax. It impairs quality of life. Nuss procedure (NP) is a minimally invasive method of PE correction. It consists in placing a curved metal bar under sternum and fixation of its ends to outer surfaces of the ribs. Postoperative (PO) period after NP is associated with severe pain because of aggressive distortion of thorax and probably intercostal nerves involvement. Gold standard of PO analgesia after NP is epidural anesthesia (EA). Common practice lies in placing the tip of EA catheter at the level corresponding to the deformity location dermatome. However, there is information in scientific literature about effective high EA during awake cardiac surgery via median sternotomy.

\section{Objective}

To compare analgesic efficacy of conventional approach to EA and high EA during and after NP.

\section{Materials and methods}

Thirty-two 13 to 16 year old children with PE were randomized into 2 groups ("Conventional", $n=18$ and "High", n=14) before NP. Intravenous induction and maintenance of anesthesia with propofol (3 $\mathrm{mg} / \mathrm{kg}$ and $6 \mathrm{mg} / \mathrm{kg}^{*}$ hour respectively) was performed. Left double lumen endotracheal tube was placed after fentanyl ( $5 \mathrm{mcg} / \mathrm{kg}$ ) and atracurium $(0.6 \mathrm{mg} / \mathrm{kg})$ administration. In "Conventional" group epidural puncture with loss of resistance technique was performed in lateral position by paramedian approach 2 interspinous spaces below the deformity level (Th7-Th8, $n=4$, Th6-Th7, $n=8$, Th5Th6, $n=7$ ) and EA catheter was advanced $3 \mathrm{~cm}$ cranially.
In "High" group epidural puncture was made at the Th2-Th3 level using the same technique. In all patients $10 \mathrm{ml}$ of bupivacaine $0.5 \%$ was injected into epidural space after test dose. Continuous infusion of $0.25 \%$ bupivacaine $4-6 \mathrm{ml} / \mathrm{h}$, NSAIDs and paracetamol were administered to all patients after surgery. Morphine $0.1 \mathrm{mg} / \mathrm{kg}$ was used as rescue analgesia when pain intensity exceeded 40 $\mathrm{mm}$ of visual analog scale. Intraoperative dose of fentanyl, PO pain scores and PO morphine consumption were registered.

\section{Results}

Intraoperative fentanyl dose between "High" and "Conventional" groups did not differ significantly (2.8 \pm 0.11 vs $3.4 \pm 0.08 \mathrm{mcg} / \mathrm{kg}^{*} \mathrm{~h}, \mathrm{P}=0.087$ ).

Postoperative pain scores and morphine dose were significantly lower in "High" group compared to "Conventional" group (21.3 \pm 3.4 vs $45.6 \pm 5.7 \mathrm{~mm}$, $P=0.021$, and $0.15 \pm 0.03$ vs $0.57 \pm 0.08 \mathrm{mg} / \mathrm{kg}^{\star}$ day, $\mathrm{P}=0.018$, respectively).

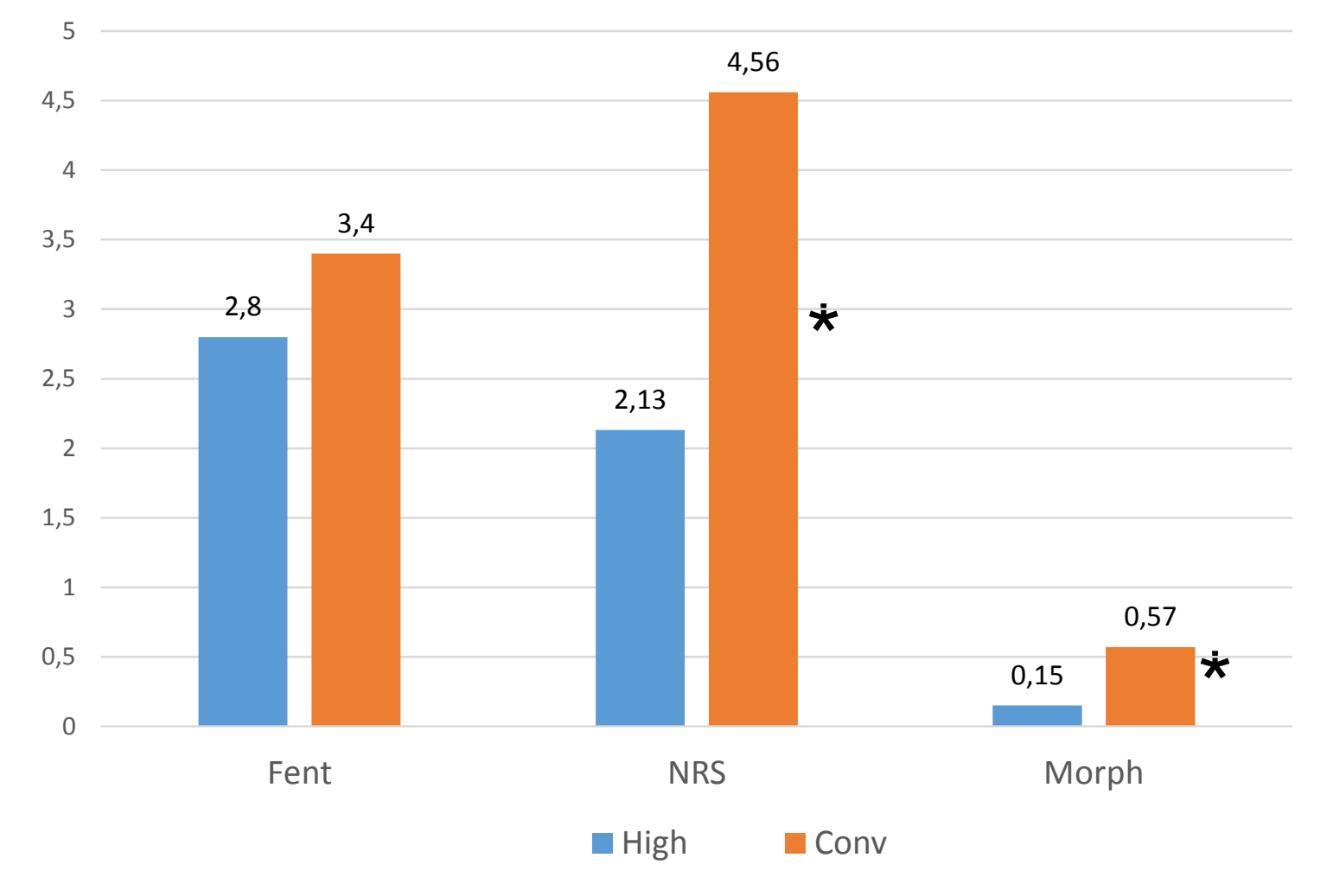

\section{Conclusion}

High EA is more effective perioperative analgesic technique in Nuss procedure compared to conventional approach to EA level. 